\title{
STUDY ON EFFECT OF FIBRES WITH CEMENT ON ENGINEERING PROPERTIES OF SOILS
}

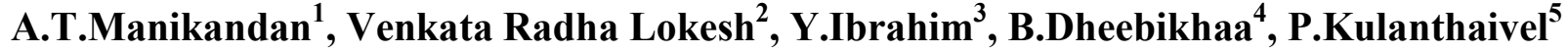 \\ ${ }^{I}$ Assistant Professor, Department of Civil Engineering, Kongu Engineering College, Erode, Tamil Nadu, India \\ ${ }^{2}$ Geotechnical Engineer, Andhra Pradesh, India \\ ${ }^{3}$ Assistant Professor, Department of Civil Engineering, B.S.Abdur Rahman University, Vandalur, Chennai, \\ Tamil Nadu, India \\ ${ }^{4}$ Environmental Engineer, Tamil Nadu, India \\ ${ }^{5}$ Assistant Professor, Department of Civil Engineering, Kongu Engineering College, Erode, Tamil Nadu, India
}

\begin{abstract}
With the increased global demand for energy and increasing local demand for aggregates, it has become expensive to remove inferior soils and replace them with strong materials. One way to overcome this problem is to improve the existing soil enough to provide strength and conform to engineering standards. Two soil samples, Black cotton soil and Sandy soil were stabilized using a natural fibre Coir and a synthetic fibre Nylon. Former is a problematic soil because of its expansive nature. Although the second sample is not problematic in nature, it is used in this study to compare the influence of stabilization for different soil types. In order to stabilize the soil, both stabilization and reinforcement techniques are adopted. The soil samples were treated with cement and then fibres were added randomly at 0.5, 1 and 1.5\% by weight of soil sample taken for different aspect ratios of 50 and 100. A series of California Bearing Ratio Tests and Unconfined Compressive Strength Tests were conducted and the best optimum proportions of fibres were determined.
\end{abstract}

Keywords: Synthetic Fibre, Natural Fibre, Black Cotton Soil, Unconfined Compressive Strength.

\section{INTRODUCTION}

The properties of problematic soils are improved by stabilization and reinforcement techniques to make the construction feasible on such soils. The soil is first treated with $5 \%$ of cement and reinforced with Coir \& Nylon at different proportions say $0.5 \%, 1.0 \%$ and $1.5 \%$ with two different aspect ratios of 50 and 100. The effect of different proportions of fibres on parameters like California Bearing Ratio and Compressive strength of both the samples treated with cement have been studied and the optimum percentage of fibres has been obtained.

Inclusions of fibres as soil reinforcement increase the compressive strength, stability, bearing capacity and reduce lateral deformation and settlements. It also prevents the formation of tension cracks. The fibres are randomly oriented to offer strength isotropy and to limit potential planes of weakness that can develop parallel to oriented reinforcement.

\subsection{Soil Sample}

The first sample was collected at a depth of $1.5 \mathrm{~m}$ near a lake located at Guduvanchery and the second sample was collected at a depth of $1.5-2 \mathrm{~m}$ at Potheri of Kanchipuram District, Tamilnadu. The samples obtained are disturbed samples that are collected by using digging rod and shovel.

\subsection{Fibres}

The Coir Fibre is collected from Broadway, Chennai, Tamilnadu. The diameter of the coir fibre varies from $0.1 \mathrm{~mm}$ to $0.3 \mathrm{~mm}$. The average diameter of $0.2 \mathrm{~mm}$ is taken for this investigation. The Synthetic Fibre i.e. Nylon Fibre is collected from Parrys, Chennai, Tamil Nadu. The diameter of Nylon Fibre is $0.2 \mathrm{~mm}$. Both the fibres are cut to lengths of $10 \mathrm{~mm}$ and $20 \mathrm{~mm}$ for aspect ratios $(1 / \mathrm{d})$ of 50 and 100 respectively.

\subsection{Cement}

Ordinary Portland Cement (OPC of Grade 53) is collected from Chettinad Cements, Chennai. Its principal advantage is that it can easily bind the soil and fibres upon the addition of water.

\section{RESULTS AND DISCUSSIONS}

The results of virgin clay and virgin sand done according to the experimental program are as follows. The liquid limit, plastic limit, specific gravity, free swell index, Optimum Moisture Content, Maximum Dry Density, Unconfined Compressive Strength and CBR value of clay are $52 \%$, $19.2 \%, 2.37,70 \%, 22.5 \%, 1.6 \mathrm{~g} / \mathrm{cc}, 1.045 \mathrm{~kg} / \mathrm{cm}^{2} \& 3.9 \%$ respectively. The liquid limit, plastic limit, specific gravity, Optimum Moisture Content, Maximum Dry Density, Unconfined Compressive Strength and CBR value of sand are $79 \%, 51 \%, 2.52,11.5 \%, 1.93 \mathrm{~g} / \mathrm{cc}, 1.7 \mathrm{~kg} / \mathrm{cm}^{2}$ and $4.2 \%$ respectively. 
The virgin clay and sand are then mixed with $5 \%$ of cement and reinforced with Coir \& Nylon at different proportions of fibres say $0.5 \%, 1.0 \% \& 1.5 \%$ with two different aspect ratios of 50 and 100 . The test results are as follows.

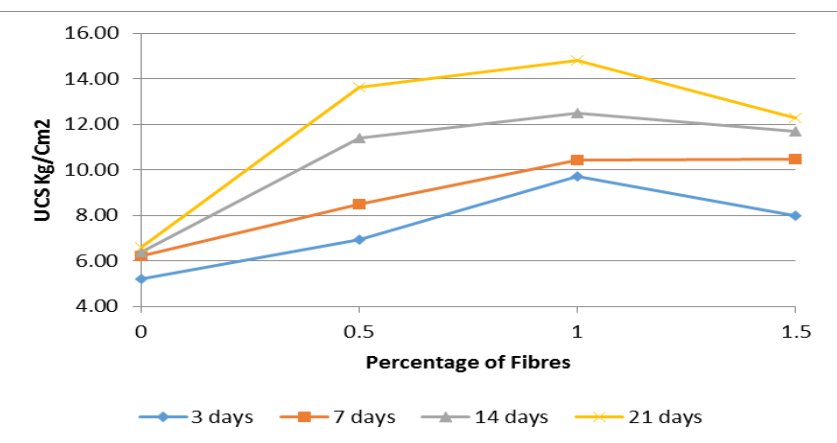

Chart -1: Variation of UCS with Coir Fibre for AR 50 for clay

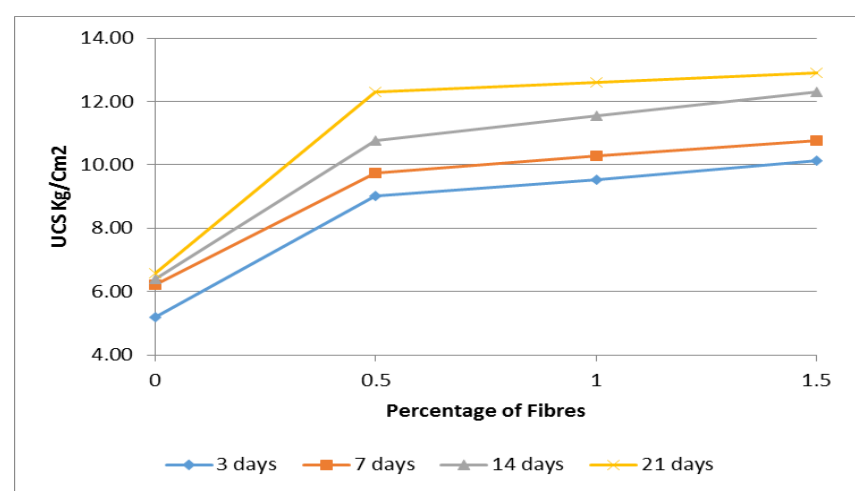

Chart -2: Variation of UCS with Coir Fibre for AR 100 for clay

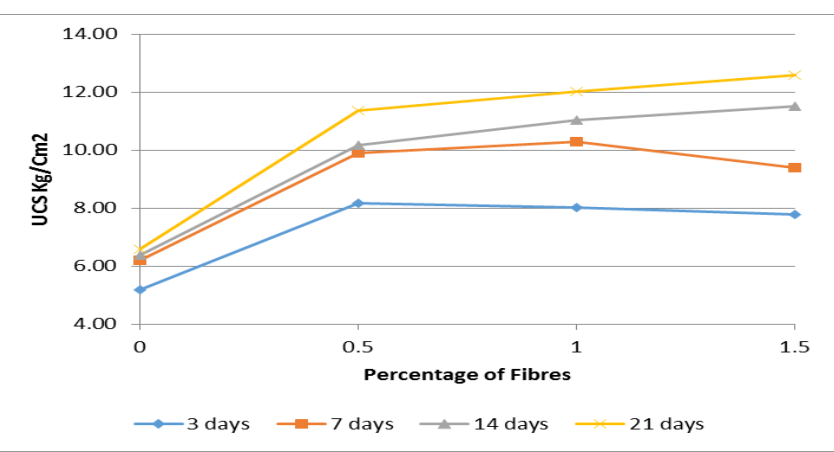

Chart -3: Variation of UCS with Nylon Fibre for AR 50 for clay

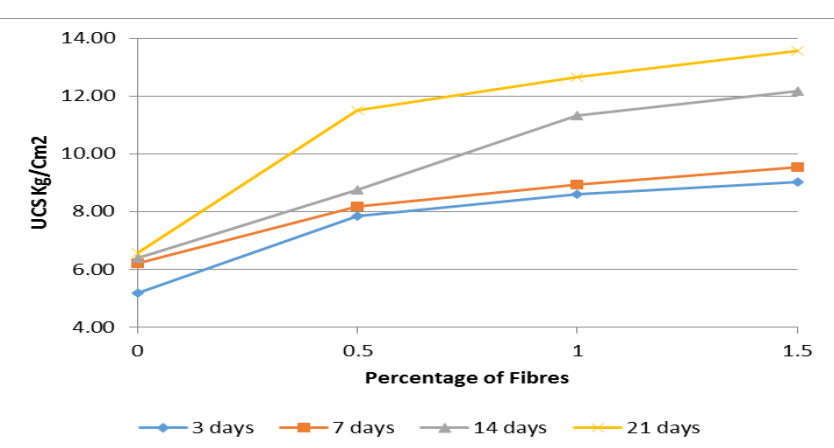

Chart -4: Variation of UCS with Nylon Fibre for AR 100 for clay

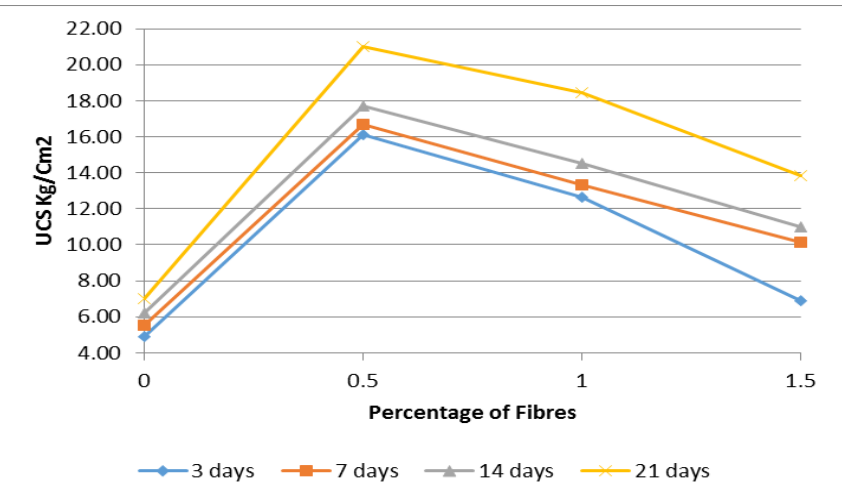

Chart -5: Variation of UCS with Coir Fibre for AR 50 for sand

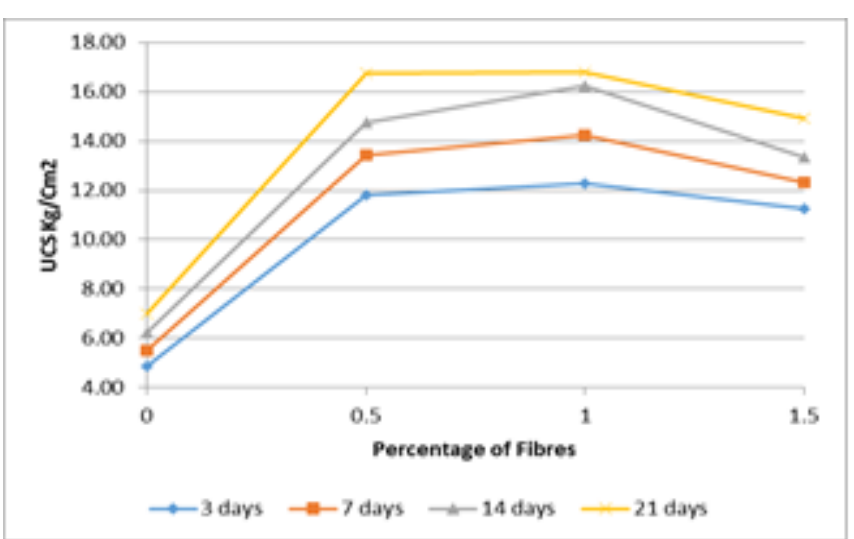

Chart -6: Variation of UCS with Coir Fibre for AR 100 for sand

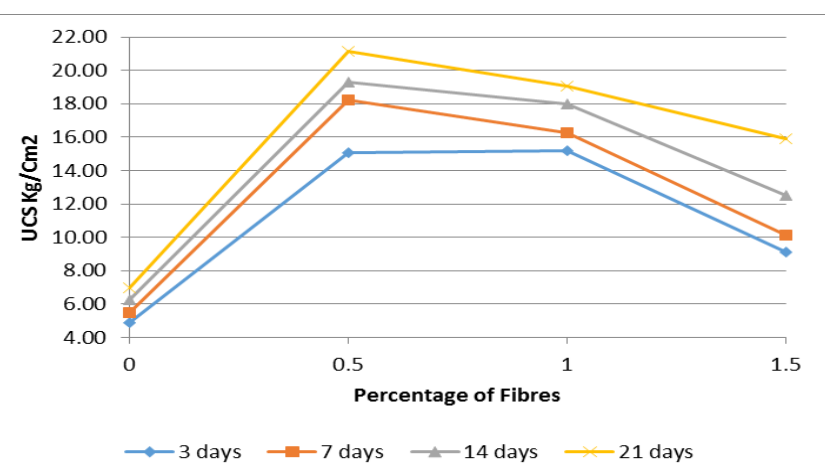

Chart -7: Variation of UCS with Nylon Fibre for AR 50 for sand

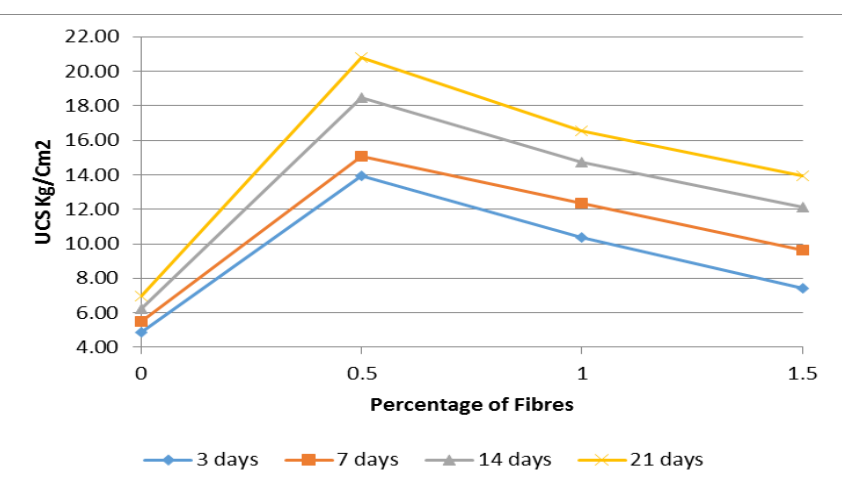

Chart -8: Variation of UCS with Nylon Fibre for AR 100 for sand 


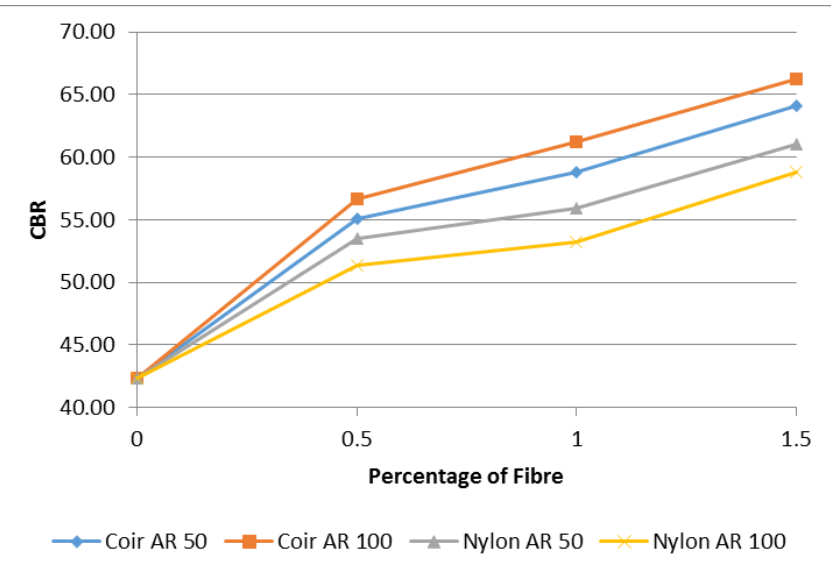

Chart -9: Variation of CBR for Clay

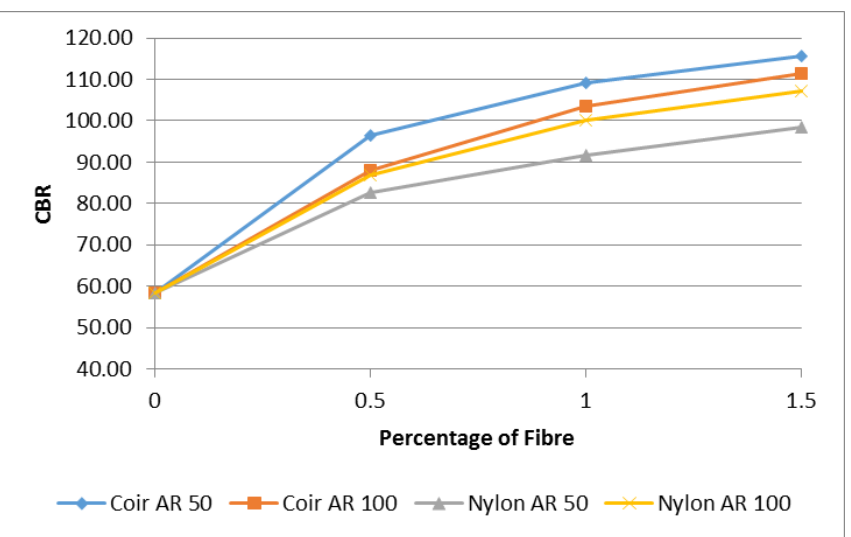

Chart -10: Variation of CBR for Sand

The CBR of treated Clay $(\mathrm{CH})$ and Sand $(\mathrm{SM})$ increases linearly with the increase in percentage of fibres. The general trend shows that the UCS of treated clay increases in most of the cases with the increase in percentage of fibres for both Coir and Nylon fibres. The maximum values of CBR \& UCS are achieved at $1.5 \%$ for both Coir and Nylon Fibres. The increase in strength with the increase in fibre content is due to the increase in absorption of water content from the soil and also due to the interlocking of fibre with the soil matrix. The CBR and UCS of both the samples increased with the increase in curing period. The maximum values were achieved for a curing time of 21 days .As the curing time increases the water content in the soil decreases. This favours the decrease in cohesion and also enhances the friction between fibre and soil particles.

The CBR of treated Clay $(\mathrm{CH})$ is maximum for an Aspect Ratio of 100 for both Coir and Nylon Fibre. The CBR of treated sand (SM) is maximum for an Aspect Ratio of 50 for Coir Fibre and Aspect Ratio of 100 Nylon Fibre. The UCS values of treated clay $(\mathrm{CH})$ are almost the same for both the Aspect Ratios (50 and 100) for both Coir and Nylon fibres. The increase in length of fibres may result in a better interlocking mechanism, by providing a larger area of contact with the soil particles.

\section{CONCLUSION}

\section{Percentage of Fibers}

- $\quad$ The CBR of treated Clay (CH) and Sand (SM) increases linearly with the increase in percentage of fibres. The Maximum value of CBR is achieved at $1.5 \%$ of both Coir and Nylon Fibres.

- The general trend shows that the UCS $\left(\mathrm{q}_{\mathrm{u}}\right)$ of treated clay increases in most of the cases with the increase in percentage of fibres for both Coir and Nylon Fibres. The maximum value is achieved at $1.5 \%$ of fibre content.

- The increase in strength with the increase in fibre content is due to the increase in absorption of water content from the soil and also due to the interlocking of fibre with the soil matrix.

\section{Curing Period}

- The CBR and UCS $\left(\mathrm{q}_{\mathrm{u}}\right)$ of both the samples increased with the increase in curing period. The maximum values were achieved for a curing time of 21 days.

- As the curing time increases the water content in the soil decreases. This favours the decrease in cohesion and also enhances the friction between fibre and soil particles.

- Aspect Ratio:

- The CBR of treated Clay $(\mathrm{CH})$ is Maximum for an Aspect Ratio of 100 for both Coir and Nylon Fibre.

- The CBR of treated sand (SM) is Maximum for an Aspect Ratio of 50 for Coir Fibre and Aspect Ratio of 100 Nylon Fibre.

- The UCS $\left(\mathrm{q}_{\mathrm{u}}\right)$ values of treated clay $(\mathrm{CH})$ are almost the same for both the Aspect Ratios (50 and 100) for both Coir and Nylon fibres.

- The increase in length of fibres may result in a better interlocking mechanism, by providing a larger area of contact with the soil particles.

\section{Type of Fiber}

- The Maximum CBR and UCS $\left(\mathrm{q}_{\mathrm{u}}\right)$ of treated clay $(\mathrm{CH})$ is achieved when Coir Fibres are used.

- The Maximum CBR of treated sand (SM) is achieved when Coir Fibres are used and Maximum UCS $\left(\mathrm{q}_{\mathrm{u}}\right)$ is achieved when Nylon Fibres are used.

- Coir fibre performed better due to its high water absorption characteristics. Coir fibres help to reduce water content which leads to higher strength.

- The high amount of Lignin content present in Coir fibre may also contribute to higher strength. Lignin content increases the tensile strength of the fibres.

\section{REFERENCES}

[1]. A. Ramesh, M. Kumar (2009), “An experimental investigation on coir fibre and fly ash in stabilized mechanistic pavements", Geotide, IGC 2009, Guntur, India. [2]. Behzad Kalantari, Bujang B.K. Huat and Arun Prasad (2010), "Effect of Polypropylene Fibres on the California Bearing Ratio of Air Cured Stabilized Tropical Peat Soil", 
American J. of Engineering and Applied Sciences 3 (1): 1-6, 2010, ISSN 1941-7020.

[3]. A.T.Manikandan, M.Moganraj (2014), "Consolidation and Rebound Characteristics of Expansive Soil by using Lime and Bagasse Ash", International Journal of Research in Engineering and Technology, Vol.03, Issue 04, April 2014, pp 403-411.

[4]. Enokela, O.S and Alada P.O (2012), "Strength analysis of coconut fibre stabilized earth for farm structures", International Journal of Advancements in Research \& Technology, Volume 1, Issue2, July-2012, ISSN 2278-7763. [5]. George M. Filz, James K. Mitchell (23 February 2004), "Rapid stabilization/polymerization Of wet clay soils", airbase technologies division, tyndall air force base, Florida, 32403-5323.

[6]. H.N. Ramesh, K.V. Manoj Krishna, H.V.Mamatha (2011), "Strength performance of lime and sodium hydroxide treated -coir fibre reinforced soil", Proceedings of Indian Geotechnical Conference, December 15-17,2011, Kochi (Paper No. J-031)

[7]. Harry G. Poulos, Grahame Bunce (2008), "Foundation Design for the Burj Dubai - the world's tallest building", $6^{\text {th }}$ International Conference on case histories in geotechnical engineering, Arlington, VA, August 11-16, 2008.

[8]. Dhiaadin Bahaadin, Noory Zangana (2012), "The Effect Of Sodium Hydroxide On The Strength Of Kirkuk Soil Cement Mixtures", Anbar Journal for Engineering Sciences 2012, Vol.5, No.2.

[9]. A.T.Manikandan, Animesh Sharma, G.Karthick, A.Abdul Jameel (2015), "Study on Effect of Molasses on Strength of Soil", International Journal of Advanced Research Trends in Engineering and Technology, Vol.02, Issue 02, February 2015, pp 57-61.

[10]. IS: 2720(Part3/sec-1) 1980, 'Code of practise for Determination of specific gravity, BIS, New Delhi.

[11]. IS: 2720(Part 5) 1970, 'Code of practise for Determination of liquid \& plastic limit', BIS, New Delhi.

[12]. IS: 2720 (Part 7) 1972, 'Code of practise for Determination of shrinkage factors', BIS, New Delhi.

[13]. IS: 2720 (Part 7) 1980, 'Determination of moisture content-dry density relation using lite compaction', BIS, New Delhi.

[14]. IS: 2720 (Part 2) 1973, 'Code of practise for Determination of water content, BIS, New Delhi.

[15]. IS: 2720 (Part 10) 1970, 'Code of practise for Determination of Unconfined Compressive Strength', BIS, New Delhi.

[16]. IS: 2720 (Part 15) 1986, 'Code of practise for Determination of Consolidation properties, BIS, New Delhi.

[17]. IS: 2720 (Part 24) 1976, 'Code of practise for Determination of Cationic Exchange Capacity, BIS, New Delhi.

[18]. K.V. Madurwar, P.P. Dahale, A.N.Burile (2013),' Comparative Study of Black Cotton Soil Stabilization with RBI Grade 81 and Sodium Silicate', International Journal of Innovative Research in Science, Engineering and Technology, Vol. 2, Issue 2, February 2013.

[19]. Misari, S.M., Busari, L.D. and Agboire, S. (1998), 'Current Status of Sugar Cane Research and Development in Nigeria', Proceedings of National Co-ordinated Research Programme on Sugar Cane, NCRI, Badeggi, pp. 2-12.
[20]. Mir Sohail Ali and Shubhada Sunil Koranne (2011),'Performance Analysis of Expansive Soil Treated With Stone Dust and Fly Ash', EDJE, Vol. 16 [2011], Bund.I

[21]. Osinubi, K.J. and Mohammed, M.A. (2005), 'Potentials of bagasse ash as pozzolans.' Procedings. of the Nigerian Material Congress 2005 (NIMACON 2005), 17 19 November, Zaria. Nigeria, pp $41-45$. 